\title{
Family Demands and Satisfaction with Family Life During the COVID-19 Pandemic
}

\author{
Cort W. Rudolph \\ Saint Louis University \\ Hannes Zacher \\ Leipzig University
}

(C) 2021, American Psychological Association. This paper is not the copy of record and may not exactly replicate the final, authoritative version of the article. Please do not copy or cite without authors' permission. The final article will be available, upon publication, via its DOI:

$10.1037 / \mathrm{cfp} 0000170$

\section{Author Note}

Cort W. Rudolph (iD https://orcid.org/0000-0002-0536-9638

Hannes Zacher (iD https://orcid.org/0000-0001-6336-2947

The study reported in this article is funded by Volkswagen Foundation.

Cort W. Rudolph, Department of Psychology, Saint Louis University, St. Louis, MO

(USA). Hannes Zacher, Institute of Psychology - Wilhelm Wundt, Leipzig University, Leipzig, Germany.

The study reported in this article is funded by Volkswagen Foundation (Az. 96 849-1, "Work and Health in the Time of COVID-19: A Longitudinal Study").

Correspondence concerning this article may be addressed to Cort W. Rudolph, Department of Psychology, Saint Louis University, Saint Louis MO (USA), e-mail: cort.rudolph@health.slu.edu 


\begin{abstract}
Based upon theories that describe the process of family stress adaptation, we model changes in family demands and satisfaction with family life during the COVID-19 pandemic among a sample of $n=1,042$ respondents from Germany. Moreover, based on ecological perspectives on the role of family context, we consider partnership status and parental status as predictors of changes in these variables over time. Using a longitudinal research design, we model cooccurring trajectories of changes in family demands and satisfaction with family life between early April 2020 and early September 2020 using unconditional and conditional multivariate latent growth curve modeling. Results suggest that, on average, both family demands and satisfaction with family life increased across this time period and that having minor children $\leq 17$ years of age was associated with decreases in satisfaction with family life across time. Moreover, an exploratory analysis suggests that partnership status may help offset the positive relationship between parental status and family demands. These findings have implications for future research on family life during a crisis and suggest that single parents of young children should be the focus of interventions to reduce family-related stressors and increase levels of family wellbeing during times of crisis.

Keywords: Family Demands; Satisfaction with Family Life; Growth Modeling; Parenting;

Partnership
\end{abstract}


The COVID-19 pandemic has dramatically altered many aspects of people's lives, including key features of family life. The present study investigates changes in two such aspects, family demands (i.e., [non]normative stressors, strains, and/or hassles related to family life; see Patterson, 2002) and satisfaction with family life (i.e., favorable attitudes toward one's family life; see Zabriskie \& Ward, 2013), between early April 2020 and early September 2020. Family demands are important indicators of family stress (Patterson, 1988), and successfully navigating family demands contributes to the process of adjustment and adaptation to family stress (e.g., Patterson, 2002). Likewise, satisfaction with family life is an important indicator of family wellbeing, with research suggesting a positive correspondence with family cohesion, communication, and overall levels of family functioning (e.g., Poff et al., 2010).

Researchers have speculated about the broader implications of increasing family demands stemming from the COVID-19 pandemic (e.g., Rudolph et al., 2020). Moreover, recent empirical evidence has found positive relationships between satisfaction with family life and overall quality of life indices reported during the COVID-19 pandemic (Sacre et al., 2020). Thus, given their important roles in defining overall quality of family life, and their apparent role in understanding family dynamics during this pandemic, our goals with this study were twofold: First, based on theorizing regarding family stress adaptation (for a review, see Malia, 2006), we sought to model changes in family demands and satisfaction with family life that occurred during the COVID-19 pandemic in Germany. Second, based on theorizing regarding the role of family contexts in stress adaptation (e.g., Patterson, 1988, 2002), we sought to model how two central aspects of one's family ecology_ partnership status and parental status — modify changes in family demands and satisfaction with family life over time. We define partnership status as one's standing in a stable relationship (i.e., living with a stable partner or not), and we define parental 
status as the number of children one has who are $\leq 17$ years of age.

\section{Trajectories in Family Demands and Satisfaction with Family Life}

Data for the present study were collected in Germany between the beginning of April 2020 (i.e., the "early" first wave of the pandemic) and the beginning of September 2020 (i.e., the "late" first wave of the pandemic), with respondents at each measurement point reporting on their family demands and satisfaction with family life in the previous month. Understanding the course of the COVID-19 pandemic in Germany is important to appreciate the timing and context of the present study (Zacher \& Rudolph, 2021a; see online appendix Figure A1 for a timeline of the emergence and development of COVID-19 in Germany; https://osf.io/rvtnc/). Although the first cases of COVID-19 in Germany were already reported in late-January 2020, the first deaths did not occur until early-March. Two weeks later, in mid-March 2020, daycares and schools were closed with increasing restrictions on public life and businesses put in place from lateMarch 2020 until early-May 2020 when there was an "easing" of such restrictions. Even with such "easing," most daycares and schools remained closed until the beginning of the six-week summer vacation between late-June 2020 and late-July 2020 (n.b., the 16 German states differ in the start dates of vacation periods, tied to school schedules, as a means of reducing traffic congestion associated with travel to-and-from popular vacation destinations; schools reopened after the summer vacation, between early August 2020 and early September 2020). Please see the online appendix for an overview of the COVID-19 pandemic in Germany to give additional context to our investigation.

Family stress is best conceptualized as a process that occurs over time, rather than as a single event or situation that families face (Boss, 2002; Walker, 1985). Theories of family stress often describe typical trajectories of family processes in terms of an equilibrium that must be 
balanced over time (e.g., Malia, 2006; Patterson, 1988, 2002). As a process, family stress ebbs and flows over a course that is sometimes likened to a rollercoaster (Koos, 1946) as families experience various stressors that may disrupt their equilibrium. Typologies of family stressors (e.g., Boss, 2002; Nelson \& Norem, 1981) posit that those stressors which are pervasive, rapidly changing, intense, and unpredictable are particularly disruptive to family lives.

We argue that the COVID-19 pandemic has been an especially salient stressor for families due to its external, catastrophic, chronic, and ambiguous nature (Boss, 2002). Indeed, the rapid onset of the pandemic quickly and radically changed many otherwise stable features of family environments (e.g., "work from home" orders shifted day-to-day office work to the "home office"; school closings moved children to remote or online learning from home). Such shifts represent the type of non-normative stressors/strains (e.g., representing recurrent and novel daily hassles) associated with family life that represent family demands. The effort and work required to manage the shifts brought on by the pandemic is likely associated with increased time spent managing, effort afforded toward, and the overall "load" of family responsibilities.

In spite of high levels of family stress, families often display a high degree of resilience (e.g., Hawley \& DeHaan, 1996; McCubbin \& McCubbin, 1988) or hardiness (e.g., Figley, 1989) in the face of demands, and may still find ways to thrive even in the face of chronic stress (e.g., Hill, 1949). Considering the current context, at the same time they were experiencing increased demands due to the necessity of working and studying at home, as well as restrictions regarding meetings with members of other households, many families spent significantly more time with each other during the COVID-19 pandemic. Thus, despite the anticipation of a general increase in family demands over time, the pandemic also offered families an opportunity to spend more "quality time" with each other, which could serve to bolster satisfaction with family life. Indeed, 
research suggests that family leisure (e.g., free time spent with family on daily activities; "family time") is an important correlate of family quality of life indices (see Hodge et al., 2017, for a meta-analysis), including satisfaction with family life (Agate et al., 2009). Recent cross-sectional evidence has suggested that facets of family resilience (e.g., maintaining a positive outlook, flexibility, problem solving, social resources) were positively associated with emotional reactions, including satisfaction, experienced during the pandemic (Ramadhana, 2020). Moreover, German national panel data collected between May 2020 and June 2020 (n.b., a timeline encompassed by the present study) suggests a modest increase in satisfaction with family life over this time span (Huebener et al., 2020). Similar results, suggesting the maintenance of satisfaction with family life during the pandemic lockdown, were likewise found in a nationally representative study conducted in Spain (Ayuso et al., 2020).

Consistent with theories of family stress adaptation (e.g., McCubbin \& Patterson, 1983; Patterson, 1988, 2002), we argue that an adaptation process likely took place between the early and the late stage of the first wave of the pandemic. Indeed, it is likely that satisfaction with family life was initially relatively low while families were re-organizing their lives together; however, adaptation to their new situations enabled them to better manage daily family life over time, learning new routines, and ultimately benefiting family wellbeing. Accordingly, while seemingly paradoxical at first, it is likely that although family demands increased, family members also likely experienced increases in satisfaction with family life during the pandemic. Thus, in summary, we expect that family demands as well as satisfaction with family life generally increased between early April 2020 and early September 2020.

Hypothesis 1: There were increases in (a) family demands and (b) satisfaction with family life between early April and early September 2020. 


\section{The Role of Family Context}

Theories of family stress adaptation posit that a variety of contextual features in the form of adaptive resources (McCubbin \& Patterson, 1983) and capabilities (Patterson, 1988, 2002) aide in the process of stress adaptation. Such features work by offsetting demands, thereby encouraging the process of adaptation, and ultimately bolstering family wellbeing. To this end, various aspects of family ecologies (Bronfenbrenner, 1986; Ungar, 2011) serve as contextual features that can either augment or challenge one's ability to effectively manage family demands and improve family wellbeing. We consider two central features of the family context that we posit will serve opposing roles - to augment (i.e., partnership status) and to challenge (i.e., parental status; having children $\leq 17$ years old) the process of family stress adaptation.

Consistent with theories of family stress adjustment (e.g., Patterson, 1988, 2002), partnership status represents a family capability, affording one both material support and perceived/enacted social support, and potentially allowing one to share responsibilities (e.g., housework, parenting roles). Of note, social support, such as that derived from partnership, is often classified in terms of a resource itself (Blonna, 2005). In contrast, given that caring for dependent children at home is especially resource intensive, parental status may inhibit the process of family stress adjustment. Indeed, the pandemic exacerbated childcare responsibilities, as the closing of schools and daycares shifted the burden of day-to-day childcare onto parents. To this end, recent evidence suggests that although satisfaction with family life increased on average in Germany between May 2020 and June 2020, it actually decreased somewhat for individuals with children (Huebener et al., 2020).

Hypothesis 2: Partnership status was associated with (a) decreases in family demands and (b) increases in satisfaction with family life between early April and early September 2020. 
Hypothesis 3: Parental status was be associated with (a) increases in family demands and (b) decreases in satisfaction with family life between early April and early September 2020.

Although theoretically supported hypotheses regarding the independent effects of partnership status and parental status can be developed, the potential joint effects of these two variables are less clear based upon theory. For example, it could be that partnership status and parental status operate independently of one another. Alternatively, it could be that partnership status and parental status work in tandem to either buffer (e.g., having a partner may reduce the magnitude of the assumed positive relationship between parental status and family demands) or mitigate (e.g., having a partner may "flip the sign" of the assumed positive relationship between parental status and family demands). Given that there are multiple competing explanations for how these two variables could operate in tandem, and that the potential form of this joint effect is not clear as a result, we also consider exploratory analyses of the joint (i.e., interactive) effects of partnership status and parental status on family demands and satisfaction with family life.

\section{Method}

\section{Open Data and Materials}

Data for this study were collected as part of a larger longitudinal survey study concerning psychological aspects of work and employment. So far, two other studies on different topics, which are based upon different substantive variables, have been published from these data (Zacher \& Rudolph, 2021a, 2021b). All data and R code to reproduce the results outlined here and complete results of all focal, exploratory, and supporting analyses are available in an online appendix: $\underline{\text { https://osf.io/rvtnc/. }}$

\section{Respondents and Procedures}

This study was approved by the ethics board of blinded for peer review (Protocol ID\#: 
blinded for peer review). We commissioned a professional online panel company to recruit participants from a nationally representative panel in Germany. The company is ISO26362 certified by the International Organization for Standardization, which ensures high quality survey data. To be eligible, participants had to be at least 18 years old and be working full-time. The company sampled participants broadly from all 16 German states and from various occupations.

We purposely take a broad view on the definition of family in our research. Examining family dynamics among only those who are married or who are parents represents a narrow conceptualization of what constitutes a family (Frone, 2003; Sharma, 2013). Thus, we did not limit our sample to only those who were in stable relationships or who were parents. Rather, we consider partnership and parental status as substantive variables in our models.

In designing this study, we had originally planned to include measurement waves separated by 3-month time lags, starting in December 2019. However, we adapted to monthly measurement waves at the beginning of April 2020 to better understand the influence of the COVID-19 pandemic on psychological processes. Presently, we consider data collected at five time points, obtained via surveys administered during the first week of April (Time [T] 1), May, July, August, and September (T5) of 2020. Of note, because of the design of the larger study from which these data are drawn, data for the current study were not collected in June of 2020.

For the baseline survey conducted in December of 2019 (T0), $n=4,839$ persons in the company's database were contacted and $n=2,439$ persons initiated the survey and provided at least partial responses (e.g., demographics; response rate of 50.40\%). At each subsequent time point, these $n=2,439$ participants were recontacted by the panel company and invited to participate. Due to attrition of the initial sample, an additional "refresher sample" of $n=500$ participants was recruited in July 2020 by the panel company and these participants were also 
recontacted at subsequent time points. In total, $n=1,042$ of these participants provided at least partial responses on demographic and/or substantive variables from $\mathrm{T} 1$ to $\mathrm{T} 5$, constituting the sample we consider here (see online appendix Figure A1 for complete details of response rates).

Complete details of analyses to address attrition and patterns of missing data can be found in our online appendix. Given evidence in support of MAR, we used a full information maximum likelihood (FIML) approach to remediate missing data. FIML provides unbiased parameter estimates when data are MAR (Enders \& Bandalos, 2001). However, given the timing of measurements, noted attrition, and missing data, the sample sizes considered in our statistical models differ to some extent from model to model. Specifically, the unconditional model, described below, is based on $n=1,035$ participants who provided at least partial responses to our focal variables at T1 through T5 (n.b., of the $n=1,042$ T1-T5 respondents, $n=7$ did not provide responses on the focal variables considered here). Moreover, because the conditional model contains exogenous predictors collected at T1 (e.g., parental status, partnership status) wherein missingness was observed, the sample size for this model is reduced (effective $n=980$, reduced from $n=1,035$ ) because missingness on exogenous predictors cannot be accounted for by FIML.

\section{Measures}

Demographics. We assessed several key participant demographics as part of the baseline survey, collected in December 2019. These demographics were considered as control variables in our conditional growth model, described below. Namely, we assessed chronological age (i.e., years since birth), gender (i.e., coded as $1=$ "male"; 2 = "female"), educational attainment (i.e., coded as $1=$ "Lower Secondary School" to $4=$ "College/University or Technical College"), and monthly household income (i.e., coded as $1=$ " $€ 0-999 /$ Month" to 7 = “€6,000-6,999/Month").

Family demands. Three items were used to measure family demands, based on a similar 
measure of perceived demands in the domain of paid employment (i.e., Spector \& Jex, 1998).

Respondents were instructed to reflect on the past four weeks of their lives when responding to the following items: "How often does your family life require you to work very fast?," "How often does your family life require you to work very hard?," "How often is there a great deal to be done in your family life?" Responses were collected on a 7-point scale ranging from 1 (never) to 7 (always). This measure demonstrated good reliability across all five time points $\left(\alpha_{\text {range }}=.89\right.$ $\left..95, \omega_{\text {range }}=.90-.97, \mathrm{AVE}_{\text {range }}=.73-.80\right)$ and metric invariance across time; see online appendix.

Satisfaction with family life. A single item, "All in all, how satisfied were you with your family life in the last four weeks?," was used to measures satisfaction with family life. Responses were collected on a 7-point scale ranging from 1 (very dissatisfied) to 7 (very satisfied). This measure demonstrated good test-retest reliability over one- and two-month intervals $\left(r_{x y \text { mean }}=.60 ; r_{x y \text { range }}=.55-.67\right.$; see online appendix Table A2).

Partnership status. To gauge whether or not respondents were living in a stable partnership, we asked respondents, "Do you live in a stable partnership?” From this, we coded respondents' partnership status as $0=$ "no, does not have a partner" or $1=$ "yes, has a partner."

Parental status. We asked respondents to indicate how many children they have and their ages. From this, we coded the number of children at or under 17 years of age (i.e., $\leq 17$ years), and summed across these counts. Based on these responses, scores on this measure ranged from $0=$ "no children $\leq 17$ years old" to $4=$ "four children $\leq 17$ years old" (i.e., the maximum number of children $\leq 17$ years of age reported by any member of the sample was four; see online appendix Table A2). In defining parental status, we considered children $\leq 17$ years of age for several reasons. First, minor children (those $\leq 17$ years old) generally require more direct one-on-one care than older adult children (those $>17$ years old). Given the level of care required, 
having minor children is therefore a potential source of family stress, and this is especially so to the degree that one has (relatively) more minor children compared to others. Moreover, in Germany, 18 years is the official age at which people are considered adults in a legal sense.

Job Demands. To support an exploratory analysis, we also included a measure of job demands (Spector \& Jex, 1998). Respondents were instructed to reflect on the past four weeks of their lives when responding to the following items: "How often does your job require you to work very fast?," "How often does your job require you to work very hard?," and "How often is there a great deal to be done in your job?" Responses were collected on a 7-point scale ranging from 1 (never) to 7 (always). This measure demonstrated good reliability $\left(\alpha_{\text {range }}=.89-.91\right.$, $\omega_{\text {range }}$ $\left.=.89-.90, \mathrm{AVE}_{\text {range }}=.72-.76\right)$ and metric invariance across time; see online appendix.

\section{Statistical Analyses}

All analyses were conducted in R with the 'lavaan` package (Rosseel, 2012) using a robust maximum likelihood (MLR) estimator and FIML to account for missing data (Enders \& Bandalos, 2001). We tested our focal hypotheses using unconditional (i.e., Hypothesis 1) and conditional (Hypotheses 2 and 3) multivariate latent growth curve models. In such models, levels (i.e., intercepts) and changes (i.e., slopes) in family demands and satisfaction with family life were modeled simultaneously. Online appendix Figure A2 presents a graphical representation of such models. Beyond modeling substantive predictors in the conditional model, we also controlled for age, gender, educational attainment, and monthly household income. Previous research suggests that family demands and satisfaction with family life covary with age and gender (e.g., Greenstein, 2009; Harmelink, 1985; Pyke \& Coltrane, 1996). Moreover, education and income are resources that may help offset various family demands (Crooker et al., 2002).

\section{Results}


Correlations among observed variables as well as descriptive statistics for complete responders can be found in online appendix Table A2; correlations and descriptive statistics based upon the total sample are available in our online appendix. Considering first the unconditional model, fit indices derived from this model suggest that the model fit the data well: $\chi^{2}(49)=60.603, \mathrm{CFI}=.996, \mathrm{TLI}=.997, \mathrm{RMSEA}=.015, \mathrm{SRMR}=.021$. Moreover, in this model we observed interesting patterns of relationships between intercepts and slopes (i.e., "levelchange" relationships). In particular, higher initial levels of satisfaction with family life in early April 2020 were associated with (a) declines in family satisfaction $\left(r_{x y}=-.417, p<.001\right)$ and family demands $\left(r_{x y}=-.213, p=.011\right)$ from early April 2020 to early September 2020 . No other relationships between intercepts and slopes were statistically significant.

With regard to specific hypotheses, Hypothesis 1 offered that there would be increases in (a) family demands and (b) satisfaction with family life between early April 2020 and early September 2020. Upholding these predictions, we observed positive trajectories (i.e., slopes) of family demands $(B=.036, S E=.008, p<.001)$ and of satisfaction with family life $(B=.047, S E$ $=.008, p<.001)$ across this time span. This suggests that both (a) family demands and (b) satisfaction with family life increased positively, albeit modestly (i.e., average month-to-month changes of +.035 and +.047 , respectively, on a seven-point scale), between early April 2020 and early September 2020. Thus, Hypothesis 1 was supported.

Table 1 outlines relevant parameter estimates from our conditional multivariate latent growth curve model. This model fit the data well: $\chi_{(85)}^{2}=99.254, \mathrm{CFI}=.996, \mathrm{TLI}=.995$, RMSEA $=.014, \mathrm{SRMR}=.018$. Hypothesis 2 suggests that partnership status would be associated with (a) decreases in family demands and (b) increases in satisfaction with family life between early April 2020 and early September 2020. We observed that partnership status was 
not significantly related to the family demands slope; however, unexpectedly, it was negatively related to the satisfaction with family life slope $(B=-.063, S E=.022, p=.004)$. Thus, partnership status (i.e., having a partner vs. not having a partner) was associated with decreases in satisfaction with family life between early April and early September 2020, but was not related to changes in family demands. Thus, Hypothesis 2 was not supported.

Finally, Hypothesis 3 states that parental status would be associated with (a) increases in family demands and (b) decreases in satisfaction with family life between early April 2020 and early September 2020. We observed that parental status was negatively associated with the satisfaction with family life slope $(B=-.033, S E=.011, p=.002)$; however, it was not significantly related to the family demands slope. Thus, parental status (i.e., having children $\leq 17$ years old) was associated with decreases in satisfaction with family life between early April 2020 and early September 2020 but was not related to changes in family demands. Thus, Hypothesis 3 was also only partially supported; see online appendix for complete results.

\section{Exploratory Analyses}

We conducted two exploratory analyses to better understand the nature of our findings. First, we conducted an analysis to understand whether parental status and partnership status interacted in predicting levels and/or slopes in our conditional growth model. In summary, we observed a significant parental status-by-partnership status interaction predicting family demands $(B=-.053, S E=.025, p=.031)$; this effect was not significant for any other level or slope term. Simple-slopes analysis suggested that, for respondents without partners, having children $\leq 17$ was unrelated to changes in family demands $\left(B_{\text {simple }}=.020, S E=.020, p=.320\right)$. However, for respondents with partners, having children $\leq 17$ was negatively associated with changes in family demands $\left(B_{\text {simple }}=-.033, S E=.014, p=.016\right)$. Figure 1 presents a graphical depiction of these 
simple slopes. This model explained $10.90 \%\left(R^{2}=.109\right)$ of the variance in changes in family demands between early April 2020 and early September 2020, which represents a $1.9 \%\left(\Delta R^{2}=\right.$ .019) increase in explanatory power incremental to the main effects of parental status and partnership status alone (see Table 1). Thus, to some extent, the relationships between parental status and partnership status are more complex than our hypotheses anticipated.

Second, informed by work-family border theory and the associated idea of work-family spillover (e.g., Clark, 2000), we conducted an analysis to understand the role of external (i.e., job-related) demands on the (co)development of family demands and satisfaction with family life over time. To do so, we considered the measure of job demands, referenced above, and modeled it as part of an expanded version of our unconditional multivariate latent growth curve model. In summary of this analysis, we find that, like family demands, job demands increased across time in that the slope for demands was significant and positive $(B=.034, S E=.008, p<.001)$. Moreover, we observed a positive correlation between the slopes that represent family demands and job demands $\left(r_{x y}=.661, p<.001\right)$, but not between job demands and satisfaction with family life $\left(r_{x y}=-.015, p=.918\right)$. Both exploratory analyses are available in our online appendix.

\section{Sensitivity Analysis}

A sensitivity analysis showed that there were no quadratic effects of time for either family demands or satisfaction with family life (for full results, see our online appendix).

\section{Discussion}

The goals of this study were to examine changes in family demands and satisfaction with family life during the COVID-19 pandemic and to model how partnership and parental status modify these changes over time. Overall, we found mixed support for our hypotheses. Supporting Hypothesis 1, there were significant increases in (a) family demands and (b) 
satisfaction with family life between early April 2020 and early September 2020. However, Hypothesis 2 was not supported in that partnership status was not associated with decreases in family demands across this timespan and was unexpectedly associated with decreases in satisfaction with family life between early April 2020 and early September 2020. Finally, partially supporting Hypothesis 3, parental status was associated with decreases in satisfaction with family life but was unrelated to changes in family demands across this timespan.

The observation that partnership status was negatively related to satisfaction with family life is an unexpected, but interesting finding. The relationship between partnership status and the intercept of family satisfaction suggests that those with partners were more satisfied initially (i.e., at T1), but that the slope representing changes in satisfaction with family life was negative for those with partners versus those without. This might suggest that, independent of parental status, those with partners adjusted to the pandemic differently than those without, and this might speak to the way in which couples (co)navigate the challenges of the pandemic together. Importantly, we also noted that changes in family demands were unrelated to changes in satisfaction with family life from early April 2020 to early September 2020. Thus, while both family demands and satisfaction with family life increased during the pandemic, they did so independently of oneanother. Thus, it seems that even under conditions of increasing family demands, it is possible to maintain and enhance a healthy view of one's family as a whole (i.e., by preserving and increasing levels of satisfaction with family life). This notion is consistent with stressor dichotomies in other domains (e.g., the challenge-hindrance distinction). Moreover, as suggested, we noted a negative level-change relationship between initial levels of family satisfaction and changes in family demands (i.e., those with initially higher levels of family satisfaction actually saw a reduction in family demands from early April to early September 2020). Thus, it could be 
that initially higher levels of satisfaction with family life serve as a protective factor, buffering against, and indeed reducing family demands over time.

Moreover, our exploratory analysis of interactions between partnership status and parental status revealed an interesting pattern of findings. Specifically, there was no association between parental status and changes in family demands when respondents indicated that they did not have a partner. However, when respondents indicated that they did have a partner, the association between parental status and changes in family demands was negative, suggesting that family demands decreased over time for these respondents. Thus, as suggested above, it appears that partnership status mitigates the effect of parental status on family demands over time, and that the relationship between partnership status, parental status, and changes in family demands is more complex than the simple effects we anticipated in our hypotheses. This might imply that individuals with children and partners were better able to adapt to the pandemic, and more rapidly developed new routines that served to reduce family demands. Moreover, to the extent that parental status represents an objective index of family demands, this finding is supportive of the idea that partnership status may serve to buffer against the translation of objective demands (i.e., parental status, conceptualized as the number of children $\leq 17$ that one has) into their psychological manifestation as "perceived" family demands.

With regard to our exploratory analysis of job demands, the finding that positive trajectories of job and family demands tend to covary over time suggests that demands in one domain (i.e., work) may "spillover" into another domain (i.e., family). This is especially important to note, as work from home policies implemented to curtail the spread of COVID-19 have, in many cases, blurred the lines between family and other (e.g., job) roles.

\section{Limitations and Directions for Future Research}


Although our adoption of a longitudinal research design, with data collected five times across six months, is a strength of the present study, there are also some limitations to note. First, we relied on single item (i.e., satisfaction with family life) and adapted measures (i.e., family demands) that were collected via self-reports. To the former point, although single item measures are not ideal from a psychometric perspective, they provide some advantages in situations where it may be advantageous to minimize response burdens. Future research should consider expanded measures of these constructs, including multi-item measures, and measures collected from “other" (e.g., partner-report) sources. Still, the favorable psychometric qualities of these measures (i.e., high reliabilities; invariant factor structures), and the collection of data over time should bolster confidence in the validity of our conclusions.

Second, our design did not allow for the collection of "baseline" (i.e., pre-pandemic) levels of family demands or satisfaction with family life. Ideally, we would have been able to collect measures of our core constructs prior to the onset of the pandemic in Germany (e.g., in late 2019). However, we would argue that treating April 2020 as the baseline is still appropriate given the timeline of the virus' spread and the ensuing reactions and steps toward mitigation that were put in place (i.e., the first national "lockdown" in Germany occurred in mid-March 2020 and the April 2020 [T1] survey asked respondents to report on their family demands and satisfaction with family life retrospectively for March 2020). We do acknowledge that a stronger case could be made, especially related to discontinuities in the studied variables, if pre-pandemic levels could be represented herein. Finally, a note about the generalizability of our findings given patterns of attrition bears some mention here. In particular, although our attrition analyses suggest that systematic selection effects were of minimal magnitude, we should be somewhat cautious suggesting that the findings of our study are broadly generalizable given that we noted 
that attrition was more likely among women, those with lower educational attainment, and among those who had lower monthly income (see online appendix).

\section{Implications and Applications}

The results of this study inform the (re)development of family stress adaptation theories, especially the finding that positive changes in indicators of family stress (i.e., family demands) and family wellbeing (i.e., satisfaction with family life) co-occur independently of one another. It may be useful to distinguish between hindering and challenging family demands in future research, assuming that hindering demands are negatively and challenging demands are positively related to satisfaction. These findings have implications for the development of family care policies, especially to support single parents with children $\leq 17$ years old. These findings also suggest that single parents of young children should be the focus of interventions to reduce family-related stressors and increase levels of family wellbeing during crisis situations.

Moreover, our findings that age was associated negatively with levels of family demands and positively with levels of family satisfaction speak to the possibility of developmental forces responsible for higher overall levels of family wellbeing. Interventions based around crossgenerational role modeling and knowledge transfer may help to translate the skills necessary to buoy family wellbeing from relatively older to relatively younger family members (e.g., from parents to their children). Additionally, the finding that household income predicted increases in family satisfaction over time suggests that financial resources play an important role for the development of family wellbeing during the pandemic. Finally, the observation that initially higher levels of family satisfaction were associated with negative changes in family demands over time might suggest that interventions focused on increasing overall levels of satisfaction with family life might help to buffer against family demands during times of crisis. 


\section{References}

Agate, J. R., Zabriskie, R. B., Agate, S. T., \& Poff, R. (2009). Family leisure satisfaction and satisfaction with family life. Journal of Leisure Research, 41(2), 205-223. http://dx.doi.org/10.1080/00222216.2009.11950166

Ayuso, L., Requena, F., Jiménez-Rodriguez, O., \& Khamis, N. (2020). The Effects of COVID19 Confinement on the Spanish Family: Adaptation or Change?. Journal of Comparative Family Studies, e5134004. https://doi.org/10.3138/jcfs.51.3-4.004

Blonna, R. (2005). Coping with stress in a changing world (3rd ed.). Boston: McGraw-Hill.

Boss, P. (2002). Family stress management (2nd ed.). Newbury Park, CA: Sage.

Bronfenbrenner, U. (1986). Ecology of the family as a context for human development: Research perspectives. Developmental Psychology, 22(6), 723-742. http://dx.doi.org/10.1037/00121649.22.6.723

Clark, S. C. (2000). Work/family border theory: A new theory of work/family balance. Human relations, 53(6), 747-770. http://dx.doi.org/10.1177/0018726700536001

Crooker, K. J., Smith, F. L., \& Tabak, R. (2002). Creating work-family balance. Human Resource Development Review, 1, 387-419. https://doi.org/10.1177/1534484302238434

Enders, C. K., \& Bandalos, D. L. (2001). The relative performance of full information maximum likelihood estimation for missing data in structural equation models. Structural Equation Modeling, 8, 430-457. http://dx.doi.org/10.1207/S15328007SEM0803_5

Figley, C. R. (Ed.). (1989). Treating stress in families. New York: Brunner-Mazel.

Frone, M. R. (2003). Work-family balance. In J. C. Quick \& L. E. Tetrick (Eds.), Handbook of occupational health psychology (pp. 143-162). Washington, DC: American Psychological Association.

Greenstein, T. N. (2009). National context, family satisfaction, and fairness in the division of 
household labor. Journal of Marriage and Family, 71(4), 1039-1051.

http://dx.doi.org/10.1111/j.1741-3737.2009.00651.x

Harmelink, R. (1985). Gender differences in perceptions of family stressors. Unpublished doctoral dissertation. Iowa State University, Ames, Iowa (USA).

Hawley, D. R., \& DeHaan, L. (1996). Toward a definition of family resilience: Integrating lifespan and family perspectives. Family Process, 35(3), 283-298.

http://dx.doi.org/10.1111/j.1545-5300.1996.00283.x

Hill, R. (1949). Families under stress: Adjustment to the crises of war separation and reunion.

New York, Harper \& Brother

Hodge, C. J., Duerden, M. D., Layland, E. K., Lacanienta, A., Goates, M. C., \& Niu, X. M. (2017). The association between family leisure and family quality of life: A metaanalysis of data from parents and adolescents. Journal of Family Theory \& Review, 9(3), 328-346. doi: http://dx.doi.org/10.1111/jftr.12202

Huebener, M., Spiess, C., Siegel, N., \& Wagner, G. (2020). Parental well-being in times of COVID-19 in Germany. SOEP Working Papers. https://www.econstor.eu/ bitstream/10419/224088/1/1726675068.pdf

Koos, E. L. (1946). Families in trouble. New York: King's Crown Press.

Malia, J. A. (2006). Basic concepts and models of family stress. Stress, trauma, and crisis, 9(34), 141-160. http://dx.doi.org/10.1080/15434610600853717

McCubbin, H. I., \& McCubbin, M. A. (1988). Typologies of resilient families: Emerging roles of social class and ethnicity. Family Relations, 37, 247-254. http://dx.doi.org/10.2307/584557

McCubbin, H. I., \& Patterson, J. M. (1983). The family stress process: The double ABCX model of adjustment and adaptation. Marriage \& Family Review, 6(1-2), 7-37. 
http://dx.doi.org/10.1300/J002v06n01_02

Nelson, G. D., \& Norem, R. H. (1981). A process model of families and stress. Paper presented at the Theory Construction and Research Methodology Pre-Conference Workshop, National Council on Family Relations, Milwaukee, WI.

Patterson, J.M. (1988). Families experiencing stress: The family adjustment and adaptation response model. Family Systems Medicine, 5(2), 202-237.

Patterson, J. M. (2002). Integrating family resilience and family stress theory. Journal of Marriage and Family, 64(2), 349-360. http://dx.doi.org/10.1111/j.17413737.2002.00349.x

Poff, R., Zabriskie, R., \& Townsend, J. (2010). Modeling family leisure and related constructs: A national study. Journal of Leisure Research, 42, 365-391.

Pyke, K., \& Coltrane, S. (1996). Entitlement, obligation, and gratitude in family work. Journal of Family Issues, 17(1), 60-82. doi: https://doi.org/10.1177/019251396017001005

Ramadhana, M. R. (2020). A dataset for emotional reactions and family resilience during COVID-19 isolation period among Indonesian families. Data in Brief, 31, 105946.

Rosseel, Y. (2012). lavaan: An R package for structural equation modeling. Journal of Statistical Software, 48(2), 1-36. http://www.jstatsoft.org/v48/i02/

Rudolph, C. W., Allan, B., Clark, M., Hertel, G., Hirschi, A., Kunze, F., Shockley, K., Shoss, M., Sonnentag, S., \& Zacher, H. (2020). Pandemics: Implications for Research and Practice in Industrial and Organizational Psychology. Industrial and Organizational Psychology: Perspectives on Science and Practice. [In Press].

Sacre, H., Hajj, A., Badro, D. A., Selwan, C. A., Aoun, R., \& Salameh, P. (2020). The Combined Outcomes of the COVID-19 Pandemic and a Collapsing Economy on Quality of Life: A Cross-Sectional Study. Pre-Print. doi: 10.21203/rs.3.rs-34832/v1 
Sharma, R. (2013). The family and family structure classification redefined for the current times. Journal of Family Medicine and Primary care, 2(4), 306-310. https://doi.org/10.4103/2249-4863.123774

Spector, P., \& Jex, S. (1998). Development of Four Self-Report Measures of Job Stressors and Strain: Interpersonal Conflict at Work Scale, Organizational Constraints Scale, Quantitative Workload Inventory, and Physical Symptoms Inventory. Journal of Occupational Health Psychology, 3(4), 356-367. https://doi.org/10.1037/10768998.3.4.356

Ungar, M. (2011). The social ecology of resilience: Addressing contextual and cultural ambiguity of a nascent construct. American Journal of Orthopsychiatry, 81(1), 1-17. http://dx.doi.org/10.1111/j.1939-0025.2010.01067.x

Walker, A. J. (1985). Reconceptualizing family stress. Journal of Marriage and the Family, 47, 827-837. http://dx.doi.org/10.2307/352327

Zabriskie, R. B., \& Ward, P. J. (2013). Satisfaction with family life scale. Marriage \& Family Review, 49(5), 446-463. http://dx.doi.org/10.1080/01494929.2013.768321

Zacher, H., \& Rudolph, C. W. (2021a). Individual differences and changes in subjective wellbeing during the early stages of the COVID-19 pandemic. American Psychologist. http://dx.doi.org/10.1037/amp0000702

Zacher, H. \& Rudolph, C.W. (2021b). Big Five Traits as Predictors of Perceived Stressfulness of the COVID-19 Pandemic. Personality and Individual Differences. https://doi.org/ 10.1016/j.paid.2021.110694 
Table 1. Results of Multivariate Conditional Growth Model.

\begin{tabular}{|c|c|c|c|c|c|c|}
\hline Outcome & Predictors $\left(\mathrm{X} 1 \ldots \mathrm{X}_{i}\right)$ & Est. & SE & z-value & p-value & Std. Est. \\
\hline Family Demands - Intercept $\left(\mathrm{B}_{0, Y 1}\right)$ & Age & -.019 & .004 & -4.976 & $<.001$ & -.016 \\
\hline \multirow[t]{5}{*}{$\mathrm{R}^{2}=.246$} & Gender & .003 & .085 & .036 & .971 & .003 \\
\hline & Education & .053 & .043 & 1.233 & .218 & .044 \\
\hline & Income & .117 & .030 & 3.881 & $<.001$ & .099 \\
\hline & Partner Status & .522 & .101 & 5.170 & $<.001$ & .442 \\
\hline & Parental Status & .362 & .053 & 6.843 & $<.001$ & .306 \\
\hline Family Demands - Slope $\left(\mathrm{B}_{1, \mathrm{Y} 1}\right)$ & Age & $<.001$ & .001 & -.438 & .661 & -.003 \\
\hline \multirow[t]{5}{*}{$\mathrm{R}^{2}=.090$} & Gender & .006 & .018 & .309 & .757 & .047 \\
\hline & Education & .016 & .009 & 1.749 & .080 & .134 \\
\hline & Income & -.011 & .006 & -1.777 & .075 & -.094 \\
\hline & Partner Status & -.023 & .020 & -1.179 & .238 & -.198 \\
\hline & Parental Status & -.023 & .012 & -1.925 & .054 & -.194 \\
\hline Sat. Family Life - Intercept $\left(\mathrm{B}_{0, \mathrm{Y} 2}\right)$ & Age & .012 & .004 & 3.186 & .001 & .011 \\
\hline \multirow[t]{5}{*}{$\mathrm{R}^{2}=.139$} & Gender & .073 & .081 & .893 & .372 & .065 \\
\hline & Education & -.128 & .042 & -3.061 & .002 & -.114 \\
\hline & Income & .057 & .031 & 1.839 & .066 & .051 \\
\hline & Partner Status & .697 & .109 & 6.414 & $<.001$ & .620 \\
\hline & Parental Status & .061 & .046 & 1.339 & .181 & .054 \\
\hline Sat. Family Life - Slope $\left(\mathrm{B}_{1, \mathrm{Y} 1}\right)$ & Age & $<.001$ & .001 & .470 & .639 & .003 \\
\hline \multirow[t]{5}{*}{$\mathrm{R}^{2}=.109$} & Gender & .005 & .017 & .273 & .785 & .035 \\
\hline & Education & .012 & .009 & 1.376 & .169 & .089 \\
\hline & Income & .014 & .006 & 2.151 & .031 & .105 \\
\hline & Partner Status & -.063 & .022 & -2.903 & .004 & -.474 \\
\hline & Parental Status & -.033 & .011 & -3.152 & .002 & -.252 \\
\hline
\end{tabular}

Note. Est. = "Estimate," S.E. = "Standard Error of the Estimate," Std. Est. = "Standardized Estimate" Sat. Family Life = Satisfaction with Family Life. Gender, 1 = "Male"; 2 = "Female." Partnership Status $0=$ "No"; 1 = "Yes". Parental Status = No. of Children $\leq 17$ Years Old. For the sake of parsimony, only relevant model parameters (i.e., structural parameters between exogenous predictors and level/intercept and slope/change terms) are reported here. Notated parameters (e.g., $\mathrm{B}_{1, \mathrm{Y} 1} ; \mathrm{X} 1 \ldots \mathrm{X}_{\mathrm{i}}$ ) cross reference to online appendix Figure A2. For complete results, please see our online appendix. 
Figure 1. Simple Slopes for Parental Status-Partnership Status Interaction Predicting Slopes of

Family Demands.

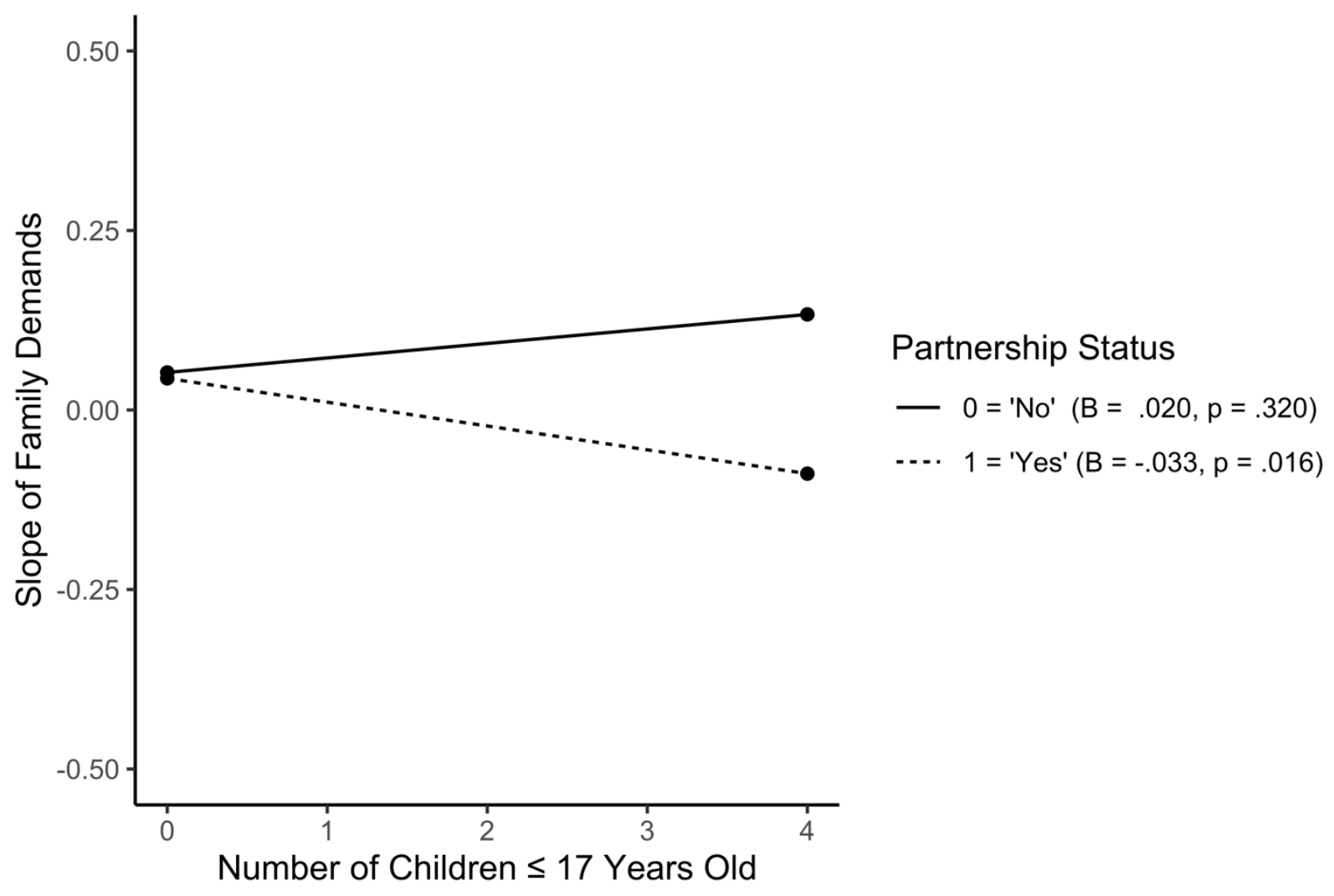

